\title{
Deposição de Calda e Controle de Plantas Daninhas EMPREgando PUlverizador De BaRRa Convencional E COM BARRA Auxiliar, em Volumes de Calda Reduzidos ${ }^{1}$
}

\author{
Spray Deposition and Weed Control using a Conventional Boom Sprayer and an Auxiliary Boom \\ Sprayer, with Reduced Spray Volumes
}

BUENO, M.R. ${ }^{2}$, CUNHA, J.P.A.R. ${ }^{2}$, NAVES, M.G. ${ }^{2}$ e TAVARES, R.M. ${ }^{2}$

\begin{abstract}
RESUMO - A tecnologia de aplicação influencia diretamente o sucesso da dessecação de présemeadura, auxiliando na eficácia de controle das plantas daninhas. $\mathrm{O}$ experimento avaliou a deposição de calda herbicida em plantas daninhas, a perda para o solo e a eficácia de controle dessas plantas promovido por duas tecnologias de aplicação (pulverizador de barra convencional e pulverizador com barra auxiliar de arrasto, variando os volumes de calda entre eles: 100 e $150 \mathrm{~L} \mathrm{ha}^{-1}$ no sistema convencional e 30 e $50 \mathrm{~L} \mathrm{ha}^{-1}$ no sistema com barra auxiliar). $\mathrm{O}$ experimento foi instalado em delineamento de blocos casualizados com cinco repetições. Foi adicionado um traçador à calda contendo o herbicida glyphosate, para ser detectado por espectrofotometria. A deposição de calda nas plantas daninhas não diferiu em função da presença ou ausência da barra auxiliar de pulverização e do volume de calda aplicado, demonstrando a viabilidade do uso de volumes de aplicação entre 30 e $50 \mathrm{~L} \mathrm{ha}^{-1}$ com a barra auxiliar. As perdas para o solo foram maiores quando foi utilizada a barra convencional do pulverizador. A eficácia de controle das plantas daninhas foi muito boa, independentemente do tratamento empregado.
\end{abstract}

Palavras-chave: dessecação, pulverização, tecnologia de aplicação.

ABSTRACT - Application technology directly influences the success of desiccation, supporting the effectiveness of weed control. This work evaluated herbicide deposition on the weeds, spray loss to the soil and the efficacy of weed control by two application technologies (conventional boom sprayer and auxiliary boom sprayer, by varying the spray volumes between them: 100 and $150 \mathrm{~L} \mathrm{hat}^{-1}$ in the conventional system and 30 and $50 \mathrm{~L} \mathrm{ha}^{-1}$ using the auxiliary boom). The experiment was conducted in a randomized block design with five replications. A tracer was added to the solution containing the herbicide glyphosate, to be detected by spectrophotometry. Spray deposition on the weeds did not differ depending on the presence or absence of the auxiliary boom, nor the spray volumes, showing the feasibility of using spray volumes between 30 and $50 \mathrm{~L} \mathrm{ha} \mathrm{H}^{-1}$ with the auxiliary boom. Soil losses were higher when the conventional spray boom was used. The efficacy of weed control was very good, regardless of the treatment used.

Keywords: desiccation, spray, application technology.

\section{INTRODUÇÃO}

No sistema de semeadura direta, o controle químico das plantas daninhas com herbicidas tornou-se uma prática constante, especialmente antes da instalação das culturas. Segundo Christoffoleti et al. (2008), a aplicação de um herbicida sistêmico-como o glyphosate, por exemplo - é uma boa alternativa devido ao seu amplo espectro de ação e à sua baixa toxicidade a organismos não alvo. Outro fator que contribuiu muito para a maior adoção desse princípio ativo foi o aumento do cultivo das culturas geneticamente modificadas.

Recebido para publicação em 4.12.2013 e aprovado em 25.1.2014.

${ }^{2}$ Universidade Federal de Uberlândia, Uberlândia, MG, Brasil, <marianarb_agro@yahoo.com.br>. 
Entretanto, na maioria das vezes dá-se muita importância ao produto fitossanitário a ser aplicado e pouca à técnica de aplicação. É preciso garantir que o produto alcance o alvo de forma eficiente, minimizando-se as perdas (Cunha, 2008).

A adoção de técnicas de aplicação adequadas, que favoreçam o depósito de produto no alvo desejado, é uma das formas de aumentar a eficiência das aplicações, além de diminuir perdas e riscos de contaminação ambiental (Cunha, 2008; Rodrigues et al., 2010; van Zyl et al., 2013). Nesse aspecto, é fundamental atentar para fatores como o pulverizador e as pontas utilizadas, tamanho e densidade de gotas, perdas para o solo e por deriva, além do volume de calda adequado para cada aplicação (Souza et al., 2011).

Fator relevante a ser considerado é a possibilidade da redução nos volumes de calda adotados, de acordo com as condições de campo (Garcerá et al., 2011). Essa alternativa possibilita o aumento da capacidade operacional dos pulverizadores e a redução de custos nas aplicações (Souza et al., 2011). Nesse sentido, com a finalidade de tentar reduzir as perdas para o solo e promover maior contato com o alvo da aplicação empregando menor consumo de calda, foi desenvolvido um acessório de pulverização para ser acoplado à barra dos pulverizadores hidráulicos convencionais. Trata-se de uma barra auxiliar de pulverização, que substitui a barra principal, dotada de pontas de pulverização ao longo de sua extensão. A altura em relação ao solo ou à cultura é regulável e bastante próxima do alvo, o que reduz o risco de deriva, mesmo com o uso de gotas mais finas.
Contudo, ainda existem muito poucos estudos sobre a eficiência real desse equipamento em campo. Assim, o presente trabalho teve como objetivo avaliar a eficácia do controle de plantas daninhas com herbicida em operação de dessecação, a deposição de calda nessas plantas e as perdas para o solo em função de diferentes volumes de calda com o uso de uma barra auxiliar de pulverização, bem como compará-la com o método convencional, empregando pulverizador com apenas a barra principal.

\section{MATERIAL E MÉTODOS}

O experimento foi conduzido no município de Uberlândia, Minas Gerais, a uma altitude de 970 metros, com 1905'39,1272's de latitude e $48^{\circ} 08^{\prime} 08,0241^{\prime \prime} \mathrm{W}$ de longitude. A área possui topografia plana, solo argiloso e estava em pousio há sete meses, visando à implantação posterior da cultura da soja na safra 2012/2013. Na safra 2011/2012, a área também foi cultivada com soja.

O delineamento experimental utilizado foi de blocos ao acaso (DBC), com cinco tratamentos e cinco repetições, totalizando 25 parcelas. Avaliou-se o controle de plantas daninhas promovido pela aplicação de herbicida em função de dois equipamentos de pulverização (pulverizador de barra convencional e dotado de barra auxiliar) e dois volumes de calda, conforme tratamentos descritos na Tabela 1. Utilizou-se também um tratamento testemunha, sem aplicação, para auxiliar na avaliação da eficácia.

As pontas, as pressões e os volumes de calda empregados na aplicação com a barra convencional foram escolhidos levando-se em

Tabela 1 - Descrição dos tratamentos avaliados

\begin{tabular}{|l|l|c|c|c|}
\hline \multicolumn{2}{|c|}{ Tratamento } & Ponta & $\begin{array}{c}\text { Pressão } \\
(\mathrm{kPa})\end{array}$ & $\begin{array}{c}\text { Volume de } \\
\text { Calda } \\
\left(\mathrm{L} \mathrm{ha}{ }^{-1}\right)\end{array}$ \\
\hline 1 & Testemunha & - & - & - \\
\hline 2 & Pulverizador de barra auxiliar & Cone vazio (MGA 80005) & 483 & 30 \\
\hline 3 & Pulverizador de barra auxiliar & Cone vazio (MGA 800067) & 689 & 50 \\
\hline 4 & Pulverizador de barra convencional & Jato plano com indução de ar (AD-IA 11002) & 310 & 100 \\
\hline 5 & Pulverizador de barra convencional & Jato plano com indução de ar (AD-IA 11002) & 448 & 150 \\
\hline
\end{tabular}


conta os tratamentos normalmente realizados pelos agricultores na região do ensaio para aplicação de herbicida visando à implantação da cultura da soja. Para as escolhas com a barra auxiliar, foram consideradas as recomendações de trabalho sugeridas pelo fabricante do equipamento. Nesse sentido, comparou-se a tecnologia convencional empregada na região com uma alternativa.

Foi utilizado o ingrediente ativo glyphosate (Crucial - sal de isopropilamina de glyphosate $40,08 \% \mathrm{~m} / \mathrm{v}$; sal de potássio de glyphosate $29,78 \% \mathrm{~m} / \mathrm{v}$ ), na dose de $4 \mathrm{~L} \mathrm{ha}^{-1}$ de produto comercial, conforme indicação de bula para o controle de Paniccum maximum.

As parcelas experimentais constaram de uma área de $100 \mathrm{~m}^{2}$, sendo $10 \mathrm{~m}$ de comprimento e $10 \mathrm{~m}$ de largura. Como área útil, foram considerados $6 \mathrm{~m}$ de comprimento e $6 \mathrm{~m}$ de largura, resultando em $36 \mathrm{~m}^{2}$.

O equipamento usado nas aplicações foi um pulverizador de arrasto hidráulico terrestre da marca Montana, modelo Ranger, dotado de tanque de $3.000 \mathrm{~L}$, com uma barra convencional de $18 \mathrm{~m}$ de comprimento e, opcionalmente, com barra auxiliar acoplada ao sistema hidráulico. A fim de facilitar as operações, trabalhou-se apenas com metade da barra. A velocidade de operação em todos os tratamentos foi de $9,5 \mathrm{~km} \mathrm{~h}^{-1}$.

A barra auxiliar (Kit Alvo $\left.{ }^{\circledR}\right)$ é constituída de um tubo resistente, com tamanho proporcional ao da barra principal do pulverizador (Figura 1). Trata-se de uma barra auxiliar de pulverização dotada de pontas de pulverização ao longo de sua extensão, voltadas para trás, com espaçamentos regulares entre os bicos, no interior da qual há uma rede de canos que comunicam a calda com as pontas. Para o seu funcionamento, a barra original do pulverizador é desativada, e o kit é acoplado à barra do pulverizador por meio de bastões flexíveis. A altura em relação ao solo ou à cultura é regulável e depende do tipo de aplicação e do estádio vegetativo da cultura, de modo que a barra auxiliar fique o mais próximo possível do solo. No presente experimento, a barra convencional ficou a $0,50 \mathrm{~m}$ de altura, e a barra auxiliar, a 0,15 m.

Em todos os tratamentos, o espaçamento entre bicos foi de $0,50 \mathrm{~m}$. As pontas de pulverização utilizadas, a pressão de trabalho e o volume de aplicação encontram-se na Tabela 1 . O reduzido volume de calda empregado com a barra auxiliar deve-se ao fato de ela, segundo o fabricante, ter sido desenvolvida para essa finalidade, visto que se pode trabalhar com gotas finas, já que a aplicação é feita próxima ao solo. É importante ressaltar que, independentemente da recomendação do fabricante, as aplicações devem ser feitas dentro de condições climáticas favoráveis à pulverização.

Antes da aplicação do herbicida, foi realizada uma estimativa da porcentagem de cobertura do solo pelas plantas daninhas incidentes na área, bem como a determinação do percentual de cada espécie, conforme a Tabela 2.

Inicialmente, foi conduzido um estudo do espectro de gotas pulverizadas, visando caracterizar melhor os tratamentos, por meio da avaliação das gotas depositadas em papéis

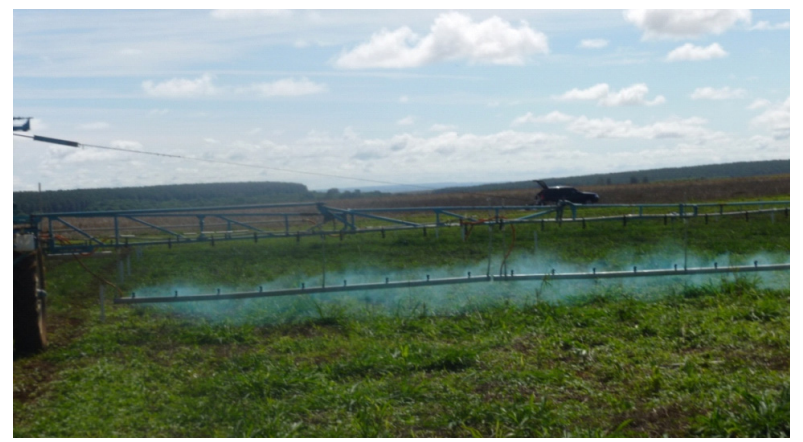

Figura 1 - Barra auxiliar acoplada ao pulverizador na área de estudo avaliada. 
Tabela 2 - Porcentagem de infestação das plantas daninhas e cobertura do solo na área estudada

\begin{tabular}{|l|c|}
\hline \multicolumn{2}{|c|}{ Porcentagem de cobertura do solo: $90 \%$} \\
\hline Planta Daninha & \% de infestação \\
\hline Paniccum maximum & 20 \\
\hline Raphanus raphanistrum & 55 \\
\hline Brachiaria plantaginea & 17 \\
\hline Ipomoea nil & 3 \\
\hline Emilia fosbergii & 2 \\
\hline Outras & 3 \\
\hline
\end{tabular}

sensiveis à água (76 x $26 \mathrm{~mm})$. Antes da pulverização, foram colocados quatro papéis hidrossensiveis em cada parcela, buscando mantê-los na posição horizontal e voltados para cima. Posteriormente, foi feita a quantificação e a caracterização dos impactos em cada papel. Para isso, os papéis foram digitalizados por meio de um scanner (resolução espacial de 600 dpi não interpolados, com cores em 24 bits) e analisados utilizando-se o programa computacional CIR 1.5 (Conteo y Tipificación de Impactos de Pulverización), específico para essa finalidade. Determinaram-se o diâmetro da mediana volumétrica (DMV), a amplitude relativa (AR) e a porcentagem do volume de gotas com diâmetro inferior a $100 \mu \mathrm{m}(\%<100)$.

A amplitude relativa foi determinada utilizando-se a seguinte equação:

$$
A R=\frac{D_{v 0,9}-D_{v 0,1}}{D_{v 0,5}}
$$

em que: $D_{v} 0,1=$ diâmetro de gota tal que $10 \%$ do volume do líquido pulverizado é constituído de gotas menores que esse valor, $\mu \mathrm{m} ; D_{v} 0,5=$ diâmetro de gota tal que $50 \%$ do volume do líquido pulverizado é constituído de gotas menores que esse valor (DMV), $\mu \mathrm{m}$; e $D_{v} 0,9=$ diâmetro de gota tal que $90 \%$ do volume do líquido pulverizado é constituído de gotas menores que esse valor, $\mu \mathrm{m}$.

Para avaliar a deposição de calda nas plantas daninhas e as perdas para o solo, foi adicionado à calda de aplicação um traçador composto do corante alimentício Azul Brilhante (catalogado internacionalmente pela Food, Drug \& Cosmetic como FD\&C Blue n.1), na dose de $300 \mathrm{~g} \mathrm{ha}^{-1}$ (ajustando-se a quantidade do corante adicionado ao tanque em função do volume de aplicação empregado), para ser detectado por absorbância em espectrofotometria.

Utilizou-se um espectrofotômetro (fotômetro fotoelétrico de filtro), com lâmpada de tungstênio-halogênio para realizar as leituras. A quantificação da coloração foi feita por absorbância em $630 \mathrm{~nm}$ - faixa de detecção do corante azul utilizado. De acordo com Pinto et al. (2007), o traçador Azul Brilhante é estável por um período de cinco horas de exposição solar.

Imediatamente após a aplicação da calda herbicida, as plantas presentes na área foram coletadas, tendo como referência um quadrado medindo $0,20 \times 0,20 \mathrm{~m}$, lançado ao acaso duas vezes em cada parcela útil para todos os tratamentos. Elas foram cortadas rente ao solo, acondicionadas em sacos plásticos e mantidas em caixa térmica, para posterior manipulação em laboratório.

A determinação de perdas de calda para o solo foi feita por meio da distribuição ao acaso de quatro lâminas de vidro $\left(37,24 \mathrm{~cm}^{2}\right.$ cada) por parcela. Após a aplicação e secagem das lâminas, elas foram recolhidas, armazenadas em sacos plásticos e mantidas em recipiente térmico.

No laboratório, foram adicionados 100 e $50 \mathrm{~mL}$ de água destilada em cada recipiente plástico contendo as plantas daninhas e as lâminas de vidro, respectivamente. Eles foram fechados e agitados por 30 segundos, para homogeneização do corante presente nas amostras. Em seguida, o líquido foi retirado e depositado em copos plásticos, os quais foram acondicionados em local refrigerado provido de isolamento luminoso por 24 horas, para posterior leitura de absorbância no espectrofotômetro.

Com o uso de curvas de calibração, obtidas por meio de soluções-padrão de corante, os dados de absorbância foram transformados em concentração $\left(\mathrm{mg} \mathrm{L}^{-1}\right)$. De posse da concentração inicial da calda e do volume de diluição das amostras, determinou-se a massa de corante retida nas plantas daninhas coletadas nas parcelas. O depósito total foi dividido pela 
massa seca de cada amostra, obtendo-se assim a quantidade em $\mathrm{mg}$ de corante $\mathrm{kg}^{-1}$ de massa seca. As plantas daninhas foram secas em estufa de circulação forçada, a $65^{\circ} \mathrm{C}$, por 72 horas. Quanto às perdas para o solo, o depósito total foi dividido pela área de remoção das lâminas, obtendo-se a quantidade em $\mu \mathrm{g}$ de corante $\mathrm{cm}^{-2}$ de lâmina.

Para análise de eficácia de controle das plantas daninhas, foram realizadas duas avaliações visuais de controle, aos 7 e 14 dias após a aplicação (DAA) do herbicida, mediante a escala de avaliação visual de controle de plantas daninhas por meio de herbicida, desenvolvida pela Asociación Latinoamericana de Malezas (ALAM, 1974).

As condições ambientais durante as aplicações foram monitoradas por meio de um termo-higro-anemômetro digital (Kestrel®) 4000). A temperatura média durante as aplicações foi de $31^{\circ} \mathrm{C}$; a umidade relativa, de 51\%; e a velocidade do vento, de $5 \mathrm{~km} \mathrm{~h}^{-1}$.

Os dados de deposição, perdas para o solo, eficácia de controle do herbicida e espectro de gotas foram primeiramente submetidos aos testes de normalidade de Kolmogorov-Smirnov e homogeneidade de Levene, com o auxílio do programa SPSS 17.0. Quando pertinente, foi realizada a análise de variância, e as médias foram comparadas pelo teste de Tukey a 0,05 de significância.

\section{RESULTADOS E DISCUSSÃO}

O resultado dos testes de normalidade e homogeneidade para as características
Tabela 3 - Resultado dos testes de pressuposições para a análise de variância

\begin{tabular}{|l|l|l|}
\hline \multirow{2}{*}{\multicolumn{1}{|c|}{ Variável }} & \multicolumn{1}{c|}{ Normalidade } & Homogeneidade \\
\cline { 2 - 3 } & \multicolumn{2}{|c|}{ Valor do teste (significância) } \\
\hline Deposição & $0,148(0,200)^{*}$ & $0,085(0,967)^{+}$ \\
\hline Perdas para o solo & $0,138(0,200)^{*}$ & $0,301(0,824)^{+}$ \\
\hline Eficácia 7 DAA & $0,195(0,046)^{* *}$ & $1,788(0,190)^{+}$ \\
\hline Eficácia 14 DAA & $0,185(0,071)^{*}$ & $2,153(0,134)^{+}$ \\
\hline DMV & $0,173(0,200)^{*}$ & $0,232(0,872)^{+}$ \\
\hline AR & $0,220(0,037)^{* *}$ & $0,400(0,756)^{+}$ \\
\hline Dv $<100$ & $0,093(0,200)^{*}$ & $1,803(0,200)^{+}$ \\
\hline
\end{tabular}

*; ** Resíduos com distribuição normal pelo teste de KolmogorovSmirnov a 0,05 e 0,01 de significância, respectivamente. ${ }^{+}$Variâncias homogêneas pelo teste de Levene a 0,05 de significância.

estudadas encontra-se na Tabela 3. Observase que, para todas as características, os resíduos apresentaram distribuição normal e as variâncias foram homogêneas, e, portanto, não houve necessidade de se fazerem transformações.

Os dados de DMV, AR e \% gotas <100 $\mu \mathrm{m}$ encontram-se na Tabela 4. Devido ao uso das pontas de jato cônico vazio, com a barra auxiliar ocorreram os menores valores de DMV e a maior porcentagem de gotas sujeitas à deriva. A AR foi menor quando se empregaram as pontas de jato cônico vazio, demonstrando maior uniformidade de tamanho das gotas. As pontas de jato cônico vazio e de jato plano com indução de ar produzem espectro de gotas bastante diferente; a maior diferença é encontrada na porcentagem de gotas pequenas (Stainier et al., 2006).

Tabela 4 - Diâmetro da mediana volumétrica (DMV, $\mu \mathrm{m}$ ), amplitude relativa (AR) e porcentagem do volume de gotas com diâmetro inferior a $100 \mu \mathrm{m}(\%<100, \%)$, em função da aplicação de glyphosate em diferentes volumes de calda, com e sem o uso de uma barra auxiliar de pulverização dotada de diferentes pontas

\begin{tabular}{|l|c|c|c|c|}
\hline \multicolumn{1}{|c|}{ Pulverizador (ponta empregada) } & $\begin{array}{c}\text { Volume de calda } \\
\left(\mathrm{L} \mathrm{ha}^{-1}\right)\end{array}$ & DMV $(\mu \mathrm{m})$ & AR & $\%<100(\%)$ \\
\hline Barra auxiliar (cone vazio) & 30 & $137,10 \mathrm{a}$ & $0,67 \mathrm{a}$ & $64,80 \mathrm{c}$ \\
\hline Barra auxiliar (cone vazio) & 50 & $156,40 \mathrm{a}$ & $0,70 \mathrm{a}$ & $40,82 \mathrm{~b}$ \\
\hline Barra convencional (jato plano com IA) & 100 & $799,47 \mathrm{~b}$ & $1,05 \mathrm{~b}$ & $1,00 \mathrm{a}$ \\
\hline Barra convencional (jato plano com IA) & 150 & $756,60 \mathrm{~b}$ & $1,17 \mathrm{~b}$ & $1,32 \mathrm{a}$ \\
\hline CV (\%) & & 12,23 & 12,28 & 11,86 \\
\hline Valor de F & & $166,748^{* *}$ & $20,591^{* *}$ & $384,820^{* *}$ \\
\hline
\end{tabular}

Médias seguidas por letras distintas nas colunas diferem entre si pelo teste de Tukey a 0,05 de significância. $* *$ significativo a 0,01 . CV: coeficiente de variação. F: valor de F calculado. 
A qualidade de uma aplicação é auxiliada pelo tamanho homogêneo das gotas pulverizadas e sua distribuição uniforme. Maiores amplitudes relativas expressam espectro de gotas mais heterogêneo; por outro lado, amplitudes tendendo a zero ilustram espectros de gotas mais homogêneos (Viana et al., 2010).

A porcentagem de gotas sujeitas à deriva, menores que $100 \mu \mathrm{m}$, foi menor para a aplicação convencional, sem a barra auxiliar para os dois volumes estudados. Quanto menor essa porcentagem, menores os riscos de deriva, apesar de não haver um valor-padrão para riscos de deriva ou aplicações seguras (Bueno et al., 2011). No entanto, resultados abaixo de $15 \%$ de volume de gotas com diâmetro inferior a $100 \mu \mathrm{m}$, em geral, sugerem aplicações mais seguras (Cunha et al., 2003). Como apresentado neste trabalho, valores de \% gotas $<100 \mu \mathrm{m}$ altos sugerem risco elevado de deriva. Entretanto, é importante destacar que a barra auxiliar trabalha mais próxima ao solo, e, dessa forma, o jato sofre menor interferência da ação dos ventos, visto que o tempo até a deposição no alvo é menor. Contudo, vale ressaltar que neste estudo não foi feita avaliação de deriva.

Quanto aos dados de deposição de calda nas plantas daninhas (Tabela 5), não houve diferença entre os tratamentos avaliados, porém, em se tratando das perdas para o solo, independentemente do volume de calda aplicado, a utilização da barra auxiliar proporcionou menores perdas. Nesse sentido, embora a deriva não tenha sido avaliada, possivelmente deve ter ocorrido maior perda atmosférica das gotas finas, de forma a equacionar o destino da aplicação: solo, planta ou perda atmosférica. Ainda que não tenham ocorrido diferentes depósitos nas plantas, o emprego da barra auxiliar permitiu maiores rendimentos operacionais, devido ao menor consumo de calda, o que se traduz em redução de custos. Possivelmente, o menor tamanho de gotas deve ter contribuído para a manutenção da cobertura, mesmo com o menor volume de calda.

Souza et al. (2012), avaliando a deposição de calda em plantas daninhas e as perdas para o solo, provenientes de aplicações do herbicida 2,4-D amina, com diferentes volumes (80 e $130 \mathrm{~L} \mathrm{ha}^{-1}$ ) e pontas de pulverização
Tabela 5 - Deposição de calda nas plantas daninhas (mg de traçador $\mathrm{kg}^{-1}$ ) e perdas para o solo $\left(\mu \mathrm{g}\right.$ de traçador $\left.\mathrm{cm}^{-2}\right) \mathrm{em}$ função da aplicação de calda herbicida contendo o traçador Azul Brilhante, em diferentes volumes de calda, com e sem o uso de uma barra auxiliar de pulverização

\begin{tabular}{|l|c|c|c|}
\hline \multicolumn{1}{|c|}{ Pulverizador } & $\begin{array}{c}\text { Volume } \\
\text { de calda } \\
\left(\mathrm{L} \mathrm{ha}^{-1}\right)\end{array}$ & $\begin{array}{c}\text { Deposição } \\
\text { de calda } \\
\left(\mathrm{mg} \mathrm{kg}^{-1}\right)\end{array}$ & $\begin{array}{c}\text { Perdas para o } \\
\text { solo } \\
\left(\mu \mathrm{g} \mathrm{cm}^{-2}\right)\end{array}$ \\
\hline Barra auxiliar & 30 & 485,230 & $1,311 \mathrm{a}$ \\
\hline Barra auxiliar & 50 & 513,917 & $1,220 \mathrm{a}$ \\
\hline Barra convencional & 100 & 684,009 & $1,739 \mathrm{~b}$ \\
\hline Barra convencional & 150 & 671,944 & $1,865 \mathrm{~b}$ \\
\hline $\mathrm{CV}(\%)$ & 37,66 & 14,48 \\
\hline Valor de F & $1,095^{\text {ns }}$ & $10,132^{*}$ \\
\hline
\end{tabular}

Médias seguidas por letras distintas na coluna diferem entre si pelo teste de Tukey a 0,05 de significância. * significativo a 0,05 . ns não significativo. $\mathrm{CV}$ : coeficiente de variação. $\mathrm{F}$ : valor de $\mathrm{F}$ calculado.

(DGTJ 60 11002, TT 11002 e TTI 11002), também verificaram que não houve diferença quanto a deposição, independentemente do volume de calda, colaborando com os resultados encontrados neste trabalho. Nesse estudo, os autores avaliaram apenas pulverizadores de barra convencional.

Rodrigues et al. (2010), entretanto, ao avaliarem a quantidade e a qualidade da deposição da calda de pulverização em plantas de Commelina benghalensis, com dois volumes de aplicação (100 e $200 \mathrm{~L} \mathrm{ha}^{-1}$ ) e cinco pontas de pulverização (TX-VK 6, TX-VK 8, XR 11001 VS, XR 11002 VS e TJ60 11002 VS), concluíram que, independentemente da ponta utilizada, o volume de $200 \mathrm{~L} \mathrm{ha}^{-1}$ proporcionou os maiores depósitos médios e pontuais nas plantas, diferindo dos resultados encontrados no presente trabalho. Uma possível explicação para essa diferença está associada às características das plantas daninhas estudadas.

Ao estudar as perdas de calda para o solo em operação de dessecação, Souza et al. (2012) verificaram que elas foram maiores nas aplicações com o maior volume de calda (130 L ha-1), independentemente da ponta de pulverização utilizada, colaborando também com os dados obtidos neste trabalho. Em contrapartida, Costa et al. (2012), ao estudarem as perdas para o solo durante a dessecação de plantas de Panicum maxicum cv. Mombaça com diferentes pontas e volumes de calda (100 e $200 \mathrm{~L} \mathrm{ha}^{-1}$ ), concluíram que as perdas 
foram menores nas aplicações com o maior volume, utilizando a ponta TX-8 VK, diferindo dos dados obtidos neste trabalho. Possivelmente, esse resultado ocorreu porque os autores estudaram o volume de $100 \mathrm{~L} \mathrm{ha}^{-1} \mathrm{com}$ gotas finas ou muito finas. Em geral, esperase que maiores volumes de calda resultem em maior escorrimento quando a área foliar não é suficiente para suportar o volume de líquido. Contudo, é dificil determinar o valor crítico a partir do qual passa a ocorrer a perda para o solo, visto que isso depende de cada espécie e do índice de área foliar, entre outros fatores.

Os dados de eficácia de controle das plantas daninhas aos 7 e 14 DAA (Tabela 6) não diferiram em função da presença ou ausência da barra auxiliar de pulverização e do volume de calda. De acordo com a escala de avaliação visual de controle de plantas daninhas (Alam, 1974), aos 7 DAA os tratamentos apresentaram boa eficácia de controle, exceto na aplicação convencional com $150 \mathrm{~L} \mathrm{ha}^{-1}$, que foi considerada muito boa. A avaliação realizada aos 14 DAA resultou em eficácia de controle considerada muito boa, demonstrando a viabilidade de todos os tratamentos.

Esse resultado está ligado à deposição nas plantas, que também não sofreu influência dos tratamentos. Novamente, as gotas finas, possivelmente, auxiliaram as aplicações com a barra auxiliar, em que se empregou baixo volume de calda. Nesse sentido, Ruas et al. (2011) concluiram que o melhor controle de Brachiaria decumbens foi obtido quando se realizou a aplicação de glyphosate com menores diâmetros de gotas, distribuídas mais uniformemente sobre as folhas das plantas. Também Knoche (1994), em vasta revisão de literatura, concluiu que a redução do tamanho de gotas resulta em aumento no desempenho de herbicidas sistêmicos.

Costa et al. (2012), ao quantificarem a eficácia do herbicida glyphosate $\left(2.160 \mathrm{~g} \mathrm{ha}^{-1}\right)$ em dessecação de Panicum maxicum cv. Mombaça com diferentes pontas e volumes de calda (100 e $200 \mathrm{~L} \mathrm{ha}^{-1}$ ), concluíram que todos os tratamentos foram eficazes no controle da graminea, independentemente da ponta e volume utilizados. Da mesma forma, Barbosa et al. (2011), ao testarem a eficácia de controle de Ipomoea nil utilizando o herbicida diuron +
Tabela 6 - Eficácia de controle das plantas daninhas (\%) aos 7 e 14 dias após a aplicação (DAA), em função da pulverização de glyphosate, em diferentes volumes de calda, com e sem o uso de uma barra auxiliar acoplada ao pulverizador

\begin{tabular}{|l|c|c|c|}
\hline \multirow{2}{*}{ Pulverizador } & \multirow{2}{*}{$\begin{array}{c}\text { Volume } \\
\text { de calda } \\
\end{array}$} & \multicolumn{2}{|c|}{$\begin{array}{c}\text { Eficácia de controle } \\
(\%)\end{array}$} \\
\cline { 3 - 4 } & $\left(\mathrm{L} \mathrm{ha}^{-1}\right)$ & 7 DAA & 14 DAA \\
\hline Barra auxiliar & 30 & 77,87 & 98,30 \\
\hline Barra auxiliar & 50 & 76,70 & 91,60 \\
\hline Barra convencional & 100 & 74,70 & 96,40 \\
\hline Barra convencional & 150 & 82,85 & 98,60 \\
\hline CV (\%) & & 25,99 & 8,24 \\
\hline Valor de F & & $0,387^{\text {ns }}$ & $0,832^{\text {ns }}$ \\
\hline
\end{tabular}

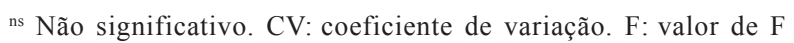
calculado.

hexazinone com e sem adjuvante, aplicado com ponta centrífuga de pulverização em diferentes volumes de calda, também constataram que, independentemente do volume de calda utilizado, não houve diferença quanto à eficácia de controle da planta daninha estudada, concordando assim com os resultados do presente trabalho. Segundo esses autores, o menor volume com niveis de controle semelhantes diminui os impactos ambientais e proporciona menor custo operacional, pois há maior rendimento na aplicação e menos reabastecimentos do tanque do pulverizador.

Por fim, é possivel concluir que a deposição de calda herbicida nas plantas daninhas não diferiu em função da presença ou ausência da barra auxiliar de pulverização e do volume de calda aplicado, o que demonstra a viabilidade do uso de volumes de aplicação entre 30 e $50 \mathrm{~L} \mathrm{ha}^{-1}$ com a barra auxiliar. As perdas de calda para o solo foram maiores quando se utilizou a barra convencional do pulverizador, nos maiores volumes de aplicação. A eficácia de controle das plantas daninhas com o herbicida glyphosate foi muito boa, independentemente do uso ou não da barra auxiliar e do volume de calda.

\section{AGRADECIMENTOS}

Ao CNPq e à Fapemig, pelo suporte financeiro parcial que permitiu o desenvolvimento deste trabalho de pesquisa. Ao Sr. Homero Fusaro, pela cessão do pulverizador. 


\section{LITERATURA CITADA}

ASOCIACIÓN LATINO AMERICANA DE MALEZAS ALAM. Recomendaciones sobre unificación de los sistemas de evaluación en ensayos de controle de malezas. Alam, v. 1 , n. 1, p. $35-38,1974$.

BARBOSA, B. F. F. et al. Controle de Ipomoea nil utilizando ponta centrífuga de pulverização em diferentes volumes de aplicação com e sem adjuvante. R. Bras. Herbic., v. 10, n. 3, p. $277-290,2011$.

BUENO, M. R. et al. Estudo do espectro de gotas produzidas nas pulverizações aérea e terrestre na cultura da batata. R. Ci. Agr., v. 54, n. 3, p. 225-234, 2011.

CHRISTOFFOLETI, P. J. et al. Aspectos da resistência de plantas daninhas a herbicidas. 3.ed. Campinas: Associação Brasileira de Ação a Resistência de Plantas Daninhas aos Herbicidas (HRAC-BR), 2008. 120 p.

COSTA, N. V. et al. Deposição de glyphosate com diferentes pontas de pulverização na dessecação de plantas de Panicum maximum. R. Bras. Herbic., v. 11, n. 1, p. 96-107, 2012.

CUNHA, J. P. A. R. et al. Avaliação de estratégias para redução da deriva de agrotóxicos em pulverizações hidráulicas. Planta Daninha, v. 21, n. 2, p. 325-332, 2003.

CUNHA, J. P. A. R. Simulação da deriva de agrotóxicos em diferentes condições de pulverização. Ci. Agrotecnol., v. 32, n. 5, p. 1616-1621, 2008.

GARCERÁ, C. et al. Effect of spray volume of two organophosphate pesticides on coverage and on mortality of California red scale Aonidiella aurantii (Maskell).

Crop Protec., v. 30, n. 6, p. 693-697, 2011.
KNOCHE, M. Effect of droplet size and carrier volume on performance of foliage-applied herbicides. Crop Protec., v. 13, n. 3, p. 163-178, 1994.

PINTO, J. R. et al. Estabilidade à exposição solar dos traçantes azul brilhante e amarelo tartrasina utilizados em estudos de deposição de pulverização. R. Bras. Agroci., v. 13, n. 1, p. 105-107, 2007.

RODRIGUES, A. C. P. et al. Avaliação qualitativa e quantitativa na deposição de calda de pulverização em Commelina benghalensis. Planta Daninha, v. 28, n. 2, p. 421-428, 2010.

RUAS, R. A. A. et al. Estimativa de parâmetros técnicos da tecnologia de aplicação do glyphosate no controle de Brachiaria decumbens. R. Ceres, v. 58, n. 3, p. 299-304, 2011

SOUZA, L. A. et al. Deposição do herbicida 2,4-D amina com diferentes volumes e pontas de pulverização em plantas infestantes. R. Ci. Agron., v. 43, n. 1, p. 78-85, 2012.

SOUZA, L. A. et al. Eficácia e perda do herbicida 2,4-D amina aplicado com diferentes volumes de calda e pontas de pulverização. Planta Daninha, v. 29, n. 2, p. 1149-1156, 2011.

STAINIER, C. et al. Droplet size spectra and drift effect of two phenmedipham formulations and four adjuvants mixtures. Crop Protec., v. 25, n. 12, p. 1238-1243, 2006.

van ZIL, J. G. et al. Spray deposition assessment and benchmarks for control of Alternaria brown spot on mandarin leaves with copper oxychloride. Crop Protec., v. 46, n. 4. p. $80-87,2013$

VIANA, R. G. et al. Distribuição volumétrica e espectro de gotas de pontas de pulverização de baixa deriva. Planta Daninha, v. 28, n. 2, p. 439-446, 2010. 